\title{
Assessment of Long Term Thermal Stress on Egyptian Coral Reefs Based on Remotely Sensed Sea Surface Temperature Data
}

\author{
Ahmed Eladawy, Kazuo Nadaoka, Abdelazim Negm, Oliver C. Saavedra, and Mahmoud Hanafy
}

\begin{abstract}
Red Sea tourism is highly dependent on the natural resources especially the diversity of Egyptian coral reefs. Local coral bleaching monitoring framework was applied in this study to investigate the threats. The target area included the six richest spots of coral reefs in terms of bio-diversity and tolerance to various stresses. Assessment of the applicability and accuracy of remotely sensed sea surface temperature (SST) data in the region were assessed by comparing them with in situ measurements. The annual and seasonal sea surface temperature (SST) trends have been investigated. Twenty three years (1990-2013) of SST data were used to assure accurate estimation of the monthly maximum mean (MMM) of SST Climatology. In addition, the Hot Spots were calculated for each location during last 23 years. A thermal stress index degree heating weeks (DHW) was calculated in order to assess the accumulative effect of heat stress. This work suggests the bleaching threshold limit for each location based on the long-term analysis. The thermal analysis results were in close agreement with the recorded bleaching events (2010 and 2012). Moreover, they revealed some historical events which may be not recorded properly.
\end{abstract}

Index Terms-Coral bleaching, sea surface temperature (SST), remote sensing, climate change, thermal stress, Egypt, Red Sea.

\section{INTRODUCTION}

Coral reefs are highly productive ecosystems that provide a variety of valuable goods and services, including recreational opportunities. The open-access nature and public good characteristics of coral reefs often result in them being undervalued in decision making related to their use and conservation [1]. They are vital ecosystems, providing a source of income, food and coastal protection for millions of people; and recent studies have shown that coral reef goods and services provide an annual net benefit of US\$30 billion to

Manuscript received December 25, 2014; revised February 2, 2015.

Ahmed El-Adawy is with the Department of Environmental Engineering, Egypt-Japan University of Science and Technology E-JUST, New Borg El-Arab, Alexandria, Egypt (e-mail: ahmed.eladawy@ejust.edu.eg).

Kazuo Nadaoka is with the Department of Mechanical and Environmental Informatics, Graduate School of Information Science and Engineering, Tokyo Institute of Technology, Tokyo, Japan (e-mail: nadaoka@mei.titech.ac.jp).

Abdelazim Negm is with Egypt-Japan University of Science and Technology E-JUST, New Borg El-Arab, Alexandria, Egypt (e-mail: negm@ejust.edu.eg).

Oliver C. Saavedra is with the Department of Civil Engineering, Graduate School of Science and Engineering, Tokyo Institute of Technology, Tokyo, Japan (e-mail: saavedra.o.aa@m.titech.ac.jp).

Mahmoud Hanafy is with Suez Canal University, Faculty of Science, Marine Science Department, Egypt (e-mail: hanafy@science.suez.edu.eg). economies worldwide [2]. Coral bleaching is the loss of pigmentation due to the breakdown of symbiosis between reef building corals and their symbiotic algae Symbiodinium (zooxanthellae). Elevated temperature is the primary cause of mass coral bleaching events [2] but recent work also suggests that organismal response to temperature variation is complex; it can depend on other biological and physiochemical factors such as the history of thermal exposure, ability to adapt or acclimate to thermal changes, short-term temperature variability, water flow, heterotrophic feeding, and light [3]. Cloud cover reduces the amount of solar radiation that can heat up the water, yet clouds reflect some of the long wave radiation emitted by the water back onto the water surface. Ocean currents can transport warmer water into cooler regions and therefore may also contribute to coral bleaching [4].

The frequency of bleaching events and mortalities has increased dramatically since 1979 [5]. Any coral bleaching prediction requires locating potential stressors, such as warm water as well as approximating the coral's reaction to that stressor. Present prediction models are based at least in part on SST which can be obtained remotely by satellite. This technique presumes that the stress caused by high temperature dominates any stress from water temperature observed in the sea [6]. Satellites offer a means by which some of the physical stressors on coral reefs can be measured. The synoptic spatial coverage and high repeat sampling frequency of such instruments allow for a quantity of data unattainable by in situ measurements [7].

The Red Sea and the Western Indian Ocean regions offer a wide variety of coastal configurations, including large areas of coral reefs. In regions that include both developed and developing countries, coral reefs and the services they provide are critical for the livelihoods, economies and well-being of local communities, while they are at risk due to both anthropogenic and natural threats [8]. The coral-reef system fronting most of the coastline of the Red Sea provides natural protection to the aquatic system. Its pronounced morphologic features protect coastal recreation facilities located behind the reef [9]. Egypt coastline possesses a significant proportion and considerable range of the coral reefs found in the Red Sea with about $3800 \mathrm{Km}^{2}$ of reef area [10]. Among the about 300 hard coral species found in the Red Sea, 2/3 are found in the Egyptian reefs, including some endemic species [11]. These numbers are higher than those recorded for the Caribbean and equal to Indian Ocean. Egyptian reefs are fringing reefs alongside the coastline. The reefs extent is in the North to the Gulfs of Suez and Aqaba to Ras Hedarba in the South at the border of Sudan. They are 
however not continuous because of periodic flooding from wadies (valleys) created gaps within reef system. The northern part of the Red Sea has the highest coral diversity and number of islands while the south has the highest terrestrial biodiversity for the whole country [12].

According to an economic study [13], the cost of coral reefs and fisheries degradation in the Egyptian Red Sea area caused by unregulated tourism activities was estimated between US\$ 2626 to 2673 million per year. These include the loss of natural capital, the loss of income from marine recreational activities, the cost of shoreline protection, and the cost of loss of fisheries resources. Uncontrolled tourism constitutes a major threat for coral reefs in two ways: directly, damage caused by tourist use of the reefs and indirectly, by anthropogenic impacts. If some reefs are highly impacted, some remain relatively remote and inaccessible and therefore not impacted by human activities, but the demand of "virgin" spots for tourism accelerates the urban and coastal development. According to studies [11], [14]-[16], the damage was basically due to the substantial increase of the number of hotels and divining boats, sedimentation and increasing water turbidity due to artificial beaches on rocky shores, and indirect impact there are sewage run-off, sedimentation following urban construction, dredging, coastal alteration and over-fishing. In the Red Sea, coral reef degradation has increased dramatically during the last three decades, particularly along the Egyptian Red Sea coast due to enhanced anthropogenic disturbances and their interaction with natural stressors [17].

Regarding natural and global impacts on coral reefs, there had been little evidence of climate change impacts on Egyptian coral reefs except two bleaching events which occurred in 2007. However, thermal stress and ocean acidification are projected to increase threat levels in the Middle East to nearly $90 \%$ of the reefs by 2030 while by 2050, these climate change impacts combined with current local impacts might induce Egyptian reefs to a threatened status [15]. A major coral bleaching event occurred in the central Red Sea near Thuwal, Saudi Arabia, in the summer of 2010, when the region experienced up to 10-11 degree heating weeks [18]. Then, the objective of this is study is to assess the remotely sensed sea surface temperature data and examine the long term characteristics of the sea surface temperature in the areas of interest. In addition, the study included calculating the seasonal and annual trends of SST. Moreover, calculating an accurate threshold for coral bleaching based on the maximum monthly mean climatology. The study will present a good base for marine biologists who are willing to investigate historical thermal stresses on the Egyptian coral reefs as a crucial part in assessing their resilience.

\section{AREAS OF INTEREST}

Six sites possesses valuable diving reefs were chosen to be investigated namely (Newbaa, Sharm El-Shiekh, Safaga, Marsa Alam and Shalatin) as shown in Fig. 1. A recent trial [19] to investigate coral bleaching events in the Egyptian coast, a survey entitled "the first recorded coral mass bleaching event" studied the coverage of bleaching event in 2012 and 2011. The main findings of the survey include the following:

1) The geographical range of the coral bleaching occurrence started from south of Qusier to far south. In comparison, there was no record for coral bleaching on the reefs of the Gulfs of Aqaba and Suez and the area between Hurghada and Safaga. This is found to be in conformity with the water circulation pattern on the Egyptian coasts of the Red sea.

2) Three main reef building species/genera included Montipora, Porites and Millipora species were severly bleached. In contrast, Acropora, stylophora, Pocillipora and soft coral affected with less extent.

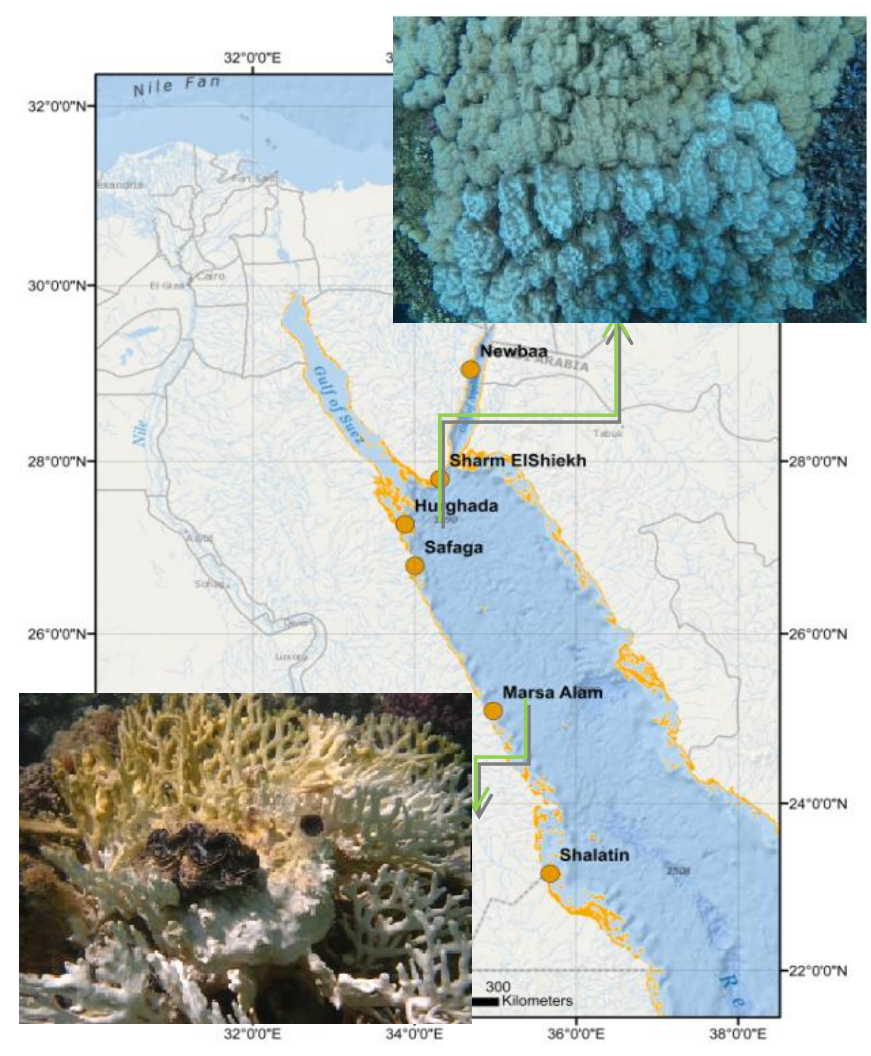

Fig. 1. On the Left: Map of areas of interest (Base map created from Ocean/world data base and overlayed by global coral reefs coverage database (available at Arc GIS Online). On the Right :Bleaching coral reefs Porites Colonies from Torfa-Near Hurghada (During bleaching event August 2012) and Millipora from Marsa Eagla -Near Marsa Alam (During bleaching event August 2012))-Unpublished Report.

\section{Methodology}

In this study, the used data included in-situ measurements and remotely sensed data. The measured data of SST have been used in order to assess the accuracy of remotely sensed sea surface temperature data.

\section{A. Remote Sensing Data}

The monthly SST time series from NOAA/NASA Pathfinder Advanced Very High Resolution Radiometer (AVHRR) Version 5.2 data of 1990-2013 (23 years), were obtained from the US National Oceanographic Data Center and Group for High-Resolution Sea Surface Temperature (GHRSST) (http://pathfinder.nodc.noaa.gov). AVHRR SST data are available at $4-\mathrm{km}$ resolution, and SST values are accurate to within $0.3^{\circ} \mathrm{C}$ [20]. All products were obtained 
from PO.DAAC. using the OPeN-DAP protocol. The dataset consists of a time series of global grids with daily temporal resolution extending back to late 1990 . The raster data were analysed using ARC GIS software in order to get the daily Sea Surface Temperature (SST) at the study sites.

\section{B. In-situ Measurements}

The sea surface temperature (SST) was collected for two years (2010-2011) at two depths of 5 and 20m, in order to test the accuracy of the data products used in this study.

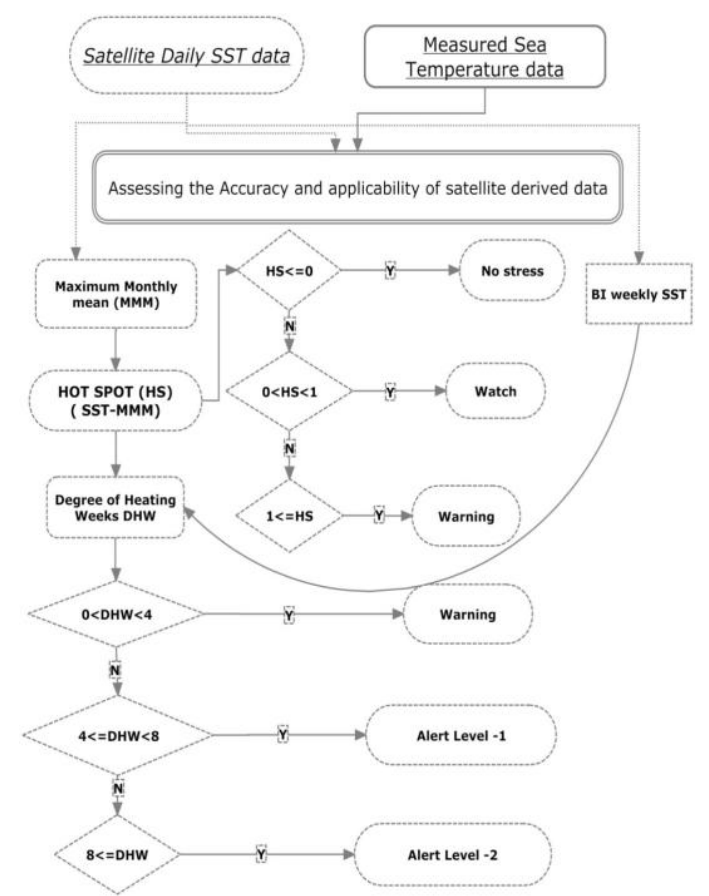

Fig. 2. Flow chart of coral bleaching monitoring based on satellite derived SST data.

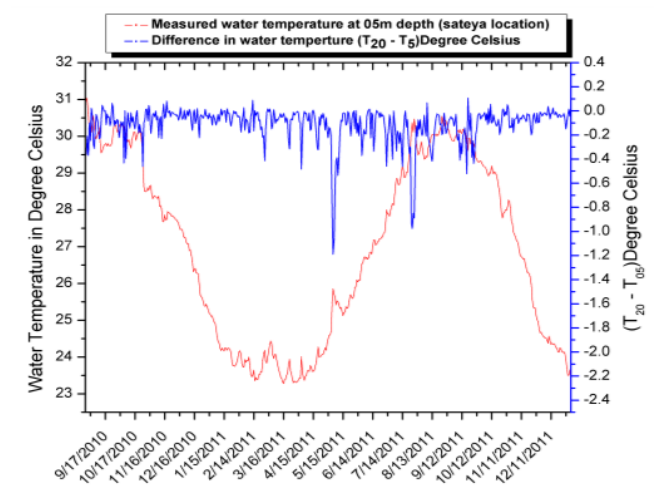

Fig. 3. The measured water temperature at $05 \mathrm{~m}$ depth (sateya location) and difference in water temperture $\left(\mathrm{T}_{20}-\mathrm{T}_{5}\right)$.

The final target of this study is to establish a local monitoring framework for coral bleaching, particularly at the highly economically valuable and diverse coral reefs along the Egyptian coast of the Red Sea, depending on the thermal stress analysis of the SST technique. The study was carried out by assessing the accuracy and applicability of satellite derived data through two steps: Comparing the remote sensing data with the field data then two different sources of remote sensing data (namely GHRSST and NOAA-AVHRR data) for the same location and time frame were compared. After assessing the applicability of using remote sensing data at the study sites, the indicators for bleaching monitoring were calculated. Fig. 2 presents diagrammatically the proposed framework for establishing local coral bleaching monitoring program.

Corals are vulnerable to bleaching when the SST exceeds the temperatures normally experienced in the hottest month. The maximum monthly mean climatology is the maximum value of the observed monthly climatology [21]. The HotSpot (HS) value shows the difference between the SST and the MMM SST climatology:

$$
\text { HotSpot = SST - MMM_SST_climatology }
$$

Degree Heating Weeks (DHW) pre accumulates the instantaneous bleaching thermal stress (measured by HotSpots) during the most-recent 12 -week period. DHW is directly related to the timing and intensity of coral bleaching [22].

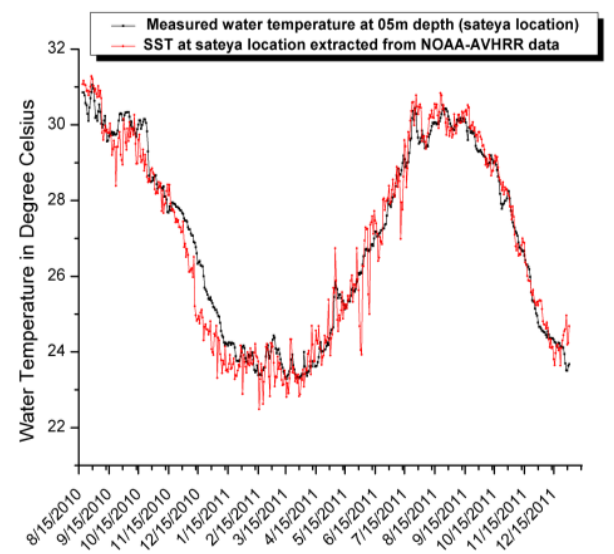

Fig. 4. Comparison between measured and remotely sensed data of SST at Sateya location.

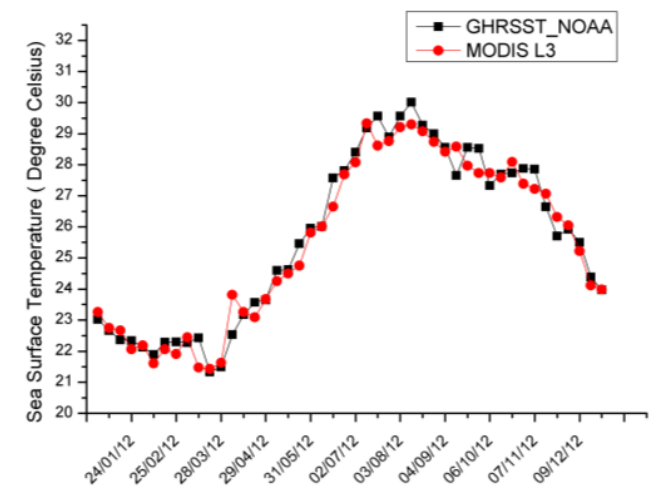

Fig. 5. Comparison between weekly averaged SST extracted from two different sensors.

Maximum monthly mean (MMM) is the first steps to calculate the Hot Spots and Degree Heating Weeks (DHW). The historical MMM of the last 23 years was calculated for each location based on the pre-mentioned remote sensing data. After that, the Hot Spots and DHW were calculated in order to find the periods of bleaching warning. The categories used to describe the severity of the bleaching are Warning, Alert Level-1 and Alert Level-2 which were estimated based on both Hot Spot and DHW. The warning status will be assessed as "Warning" when the conditions of Hot Spot $=>1{ }^{\circ} \mathrm{C}$ and $0<\mathrm{DHW}<4^{\circ} \mathrm{C}$-week were satisfied. The "Alert Level-1" was assessed when the conditions of Hot Spot $=>1{ }^{\circ} \mathrm{C}$ and $4<=\mathrm{DHW}<8^{\circ} \mathrm{C}$-week were satisfied. Whereas "Alert 
Level-2" was assessed when conditions of Hot $\mathrm{Spot}=>1{ }^{\circ} \mathrm{C}$ and $\mathrm{DHW}>=8^{\circ} \mathrm{C}$-week was satisfied. A DHW accumulation of $4^{\circ} \mathrm{C}$-weeks triggers a significant bleaching which is Alert Level-1 and bleaching is expected at the site within a few weeks. An accumulation of $8^{\circ} \mathrm{C}$-weeks triggers a strong bleaching with warning status Alert Level-2 causes widespread bleaching with severe coral mortality. Fig. 2 shows the complete framework applied in the current study.

\section{RESULTS AND DISCUSSION}

\section{A. Assessment the Accuracy and Applicability of Satellite Derived Data}

The Hurghada Environmental Protection and Conservation Association (HEPCA) installed temperature logger at Sateya location (near Marsa Alam) at two different depths $05 \mathrm{~m}$ and $20 \mathrm{~m}$. The water temperature data are recorded every hour more than 15 months. Fig. 3 shows the measured temperature data at a depth of 05 meters and the difference between the measured data at 20 meters (cooler) and 05 meters. The average difference of the temperature at the two depths was 0.11505 degree Celsius along the period of measurement. To assess the accuracy of the Sea Surface Temperature (SST) data extracted from NOAA-AVHRR, the remotely sensed data were compared to the measured water temperature on the same period of measuring. The hourly measured data were averaged to be daily data. There must be differences between SST (skin temperature) and in situ data measured at 5 but these are the only available data. The correlation coefficient $\left(\mathrm{R}^{2}\right)$ was 0.97 and the Root Mean Square Error equals 0.57 degree Celsius. Fig. 3 shows a comparison between measured water temperature at a depth 05 meters and the differences between the values at the two depths. Fig. 4 represents the values of measured and remotely sensed water temperature. Then the data from the two sensors (GHRSST_NOAA and MODIS L3) for SST in Hurghada were compared. The correlation coefficient $\left(\mathrm{R}^{2}\right)$ was 0.986 and the Root Mean Square Error equals 0.46 degree Celsius. These comparisons are shown in Fig. 5.

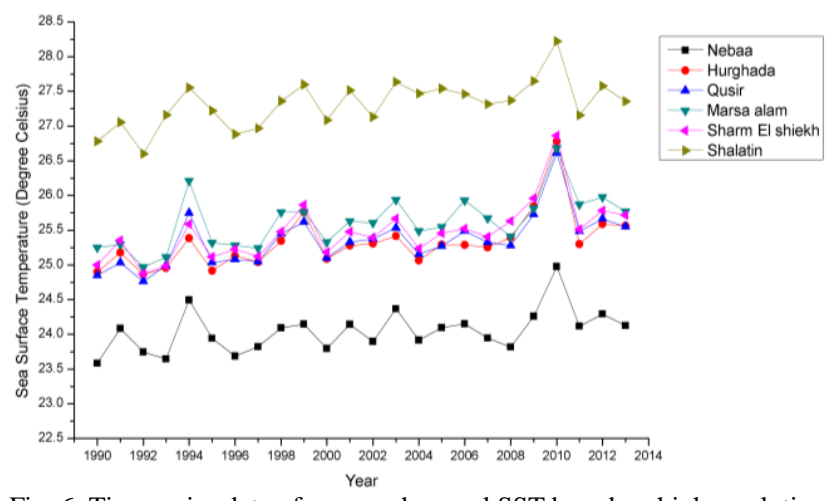

Fig. 6. Time series data of averaged annual SST based on high resolution AVHRR data on the six spots.
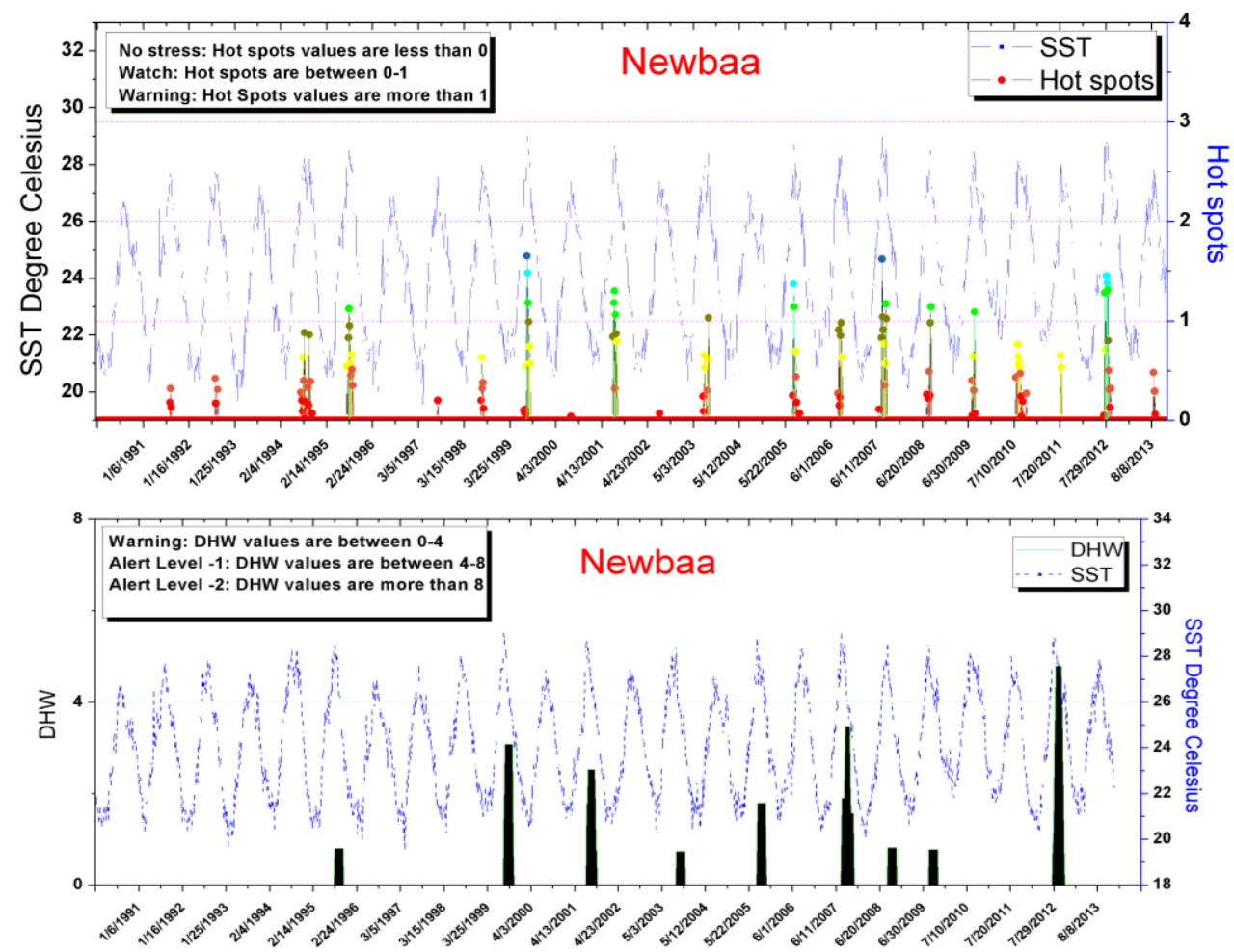

Fig. 7. Top: values of Hot Spots at Newbaa area (Note: For each year, Hot Spots values are represented in colours ranging from red to blue based on their relative intensity), Bottom: values of Degree Heating Weeks at Newbaa area during the last 23 years.

\section{B. $\quad$ Red Sea Sea Surface Temperature (SST)}

\section{Characteristics and Trends}

The time series analysis is used to reveal the SST variation between the six studied areas. All the studied sites showed an annual positive trend ranging from $0.0207^{\circ} \mathrm{C} \mathrm{yr}^{-1}$ to $0.0371^{\circ} \mathrm{C}$ $\mathrm{yr}^{-1}$. Fig. 6 and Table I show the yearly averaged SST at the six studied sites. The six studied areas displayed a range of annual average SST values of approximately $3.277{ }^{\circ} \mathrm{C}$, ranging from $24.04^{\circ} \mathrm{C}$ in Newbaa to $27.31^{\circ} \mathrm{C}$ in Shalatin. Data obtained from Shalatin sites recorded the highest standard deviation of 2.4757 , i.e. highest range as well as fluctuations in the Sea Surface Temperature along the year was measured at this site. Regarding annual trend, highest annual average 
SST was recorded in 2010. In addition, positive annual and seasonal trends were estimated at all studied locations. Analysing the seasonal trends of sea surface temperature is very critical to examine the potential impacts of increasing SST on bleaching of the coral reefs. However, it seemed that the bleaching potential is more likely to occur in August (summer). Except Shalatin, the summer trend in increasing SST is larger than the positive annual trend in the studied areas (see Table I and Fig. 6).

\section{Time Series of Hot Spots and Degree Heating Weeks}

The time series graphs of the Hot Spots (HS) and Degree Heating Weeks (DHW) were determined based on 23 years of data on different locations. The climatology of maximum monthly mean (MMM) sea surface temperature (SST) during the period was calculated in order to get accurate values for MMM at each location. Accordingly, the Hot spots (HS) and DHW (Degree Heating Weeks) were calculated. Therefore, for each studied location a threshold limit for coral bleaching at the current study point is defined as the MMM at this location. Beyond this threshold temperature, the corals will be under stress and get bleached if the higher temperature regime prolonged. In order to monitor this cumulative effect, a thermal stress index termed as Coral Bleaching Degree Heating Week (DHW) is presented. Table II. Show the calculated MMM for each studied location based on the obtained data of the last 23 years.

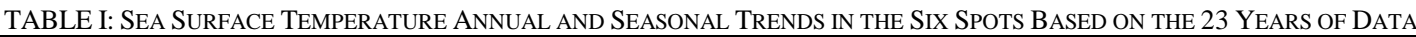

\begin{tabular}{|c|c|c|c|c|c|c|c|c|c|}
\hline \multicolumn{4}{|c|}{ Annual trend ${ }^{\circ} \mathrm{C} \mathrm{yr}^{-1}$} & \multirow[b]{2}{*}{ Summer } & \multirow[b]{2}{*}{ Autumn } & \multicolumn{4}{|c|}{ Average ${ }^{\circ} \mathrm{C} \pm$ Standard deviation } \\
\hline Location & Winter & Spring & & & & Winter & Spring & Summer & Autumn \\
\hline \multirow[t]{2}{*}{ Newbaa } & & & 0.0207 & & & \multicolumn{4}{|c|}{$24.0469 \pm 2.225$} \\
\hline & 0.0257 & 0.0112 & & 0.0288 & 0.0165 & 25.51 & 23.434 & 26.837 & 24.367 \\
\hline \multirow[t]{2}{*}{ Hurghada } & & & 0.0335 & & & \multicolumn{4}{|c|}{$25.3298 \pm 2.36919$} \\
\hline & 0.0387 & 0.0354 & & 0.0454 & 0.0139 & 22.60919 & 24.7035 & 28.1114 & 25.8529 \\
\hline \multirow[t]{2}{*}{ Qusir } & & & 0.0339 & & & \multicolumn{4}{|c|}{$25.3538 \pm 2.3825$} \\
\hline & 0.0343 & 0.0436 & & 0.0432 & 0.014 & 22.5955 & 24.8272 & 28.2409 & 25.7099 \\
\hline \multirow[t]{2}{*}{ Marsa Alam } & & & 0.0325 & & & \multicolumn{4}{|c|}{$25.6185 \pm 2.4377$} \\
\hline & 0.0302 & 0.0402 & & 0.0409 & 0.018 & 22.7438 & 25.1686 & 28.6106 & 25.9083 \\
\hline \multicolumn{3}{|c|}{ Sharm El shiekh } & 0.0371 & & & \multicolumn{4}{|c|}{$25.4748 \pm 2.365$} \\
\hline \multirow{3}{*}{ Shalatin } & 0.0378 & 0.0393 & & 0.0511 & 0.0199 & 22.744 & 24.741 & 28.1908 & 26.1789 \\
\hline & & & 0.0292 & & & \multicolumn{4}{|c|}{$27.3178 \pm 2.4757$} \\
\hline & 0.0572 & 0.0315 & & 0.0087 & 0.0183 & 24.32147505 & 26.90954 & 30.30216 & 27.69375 \\
\hline
\end{tabular}
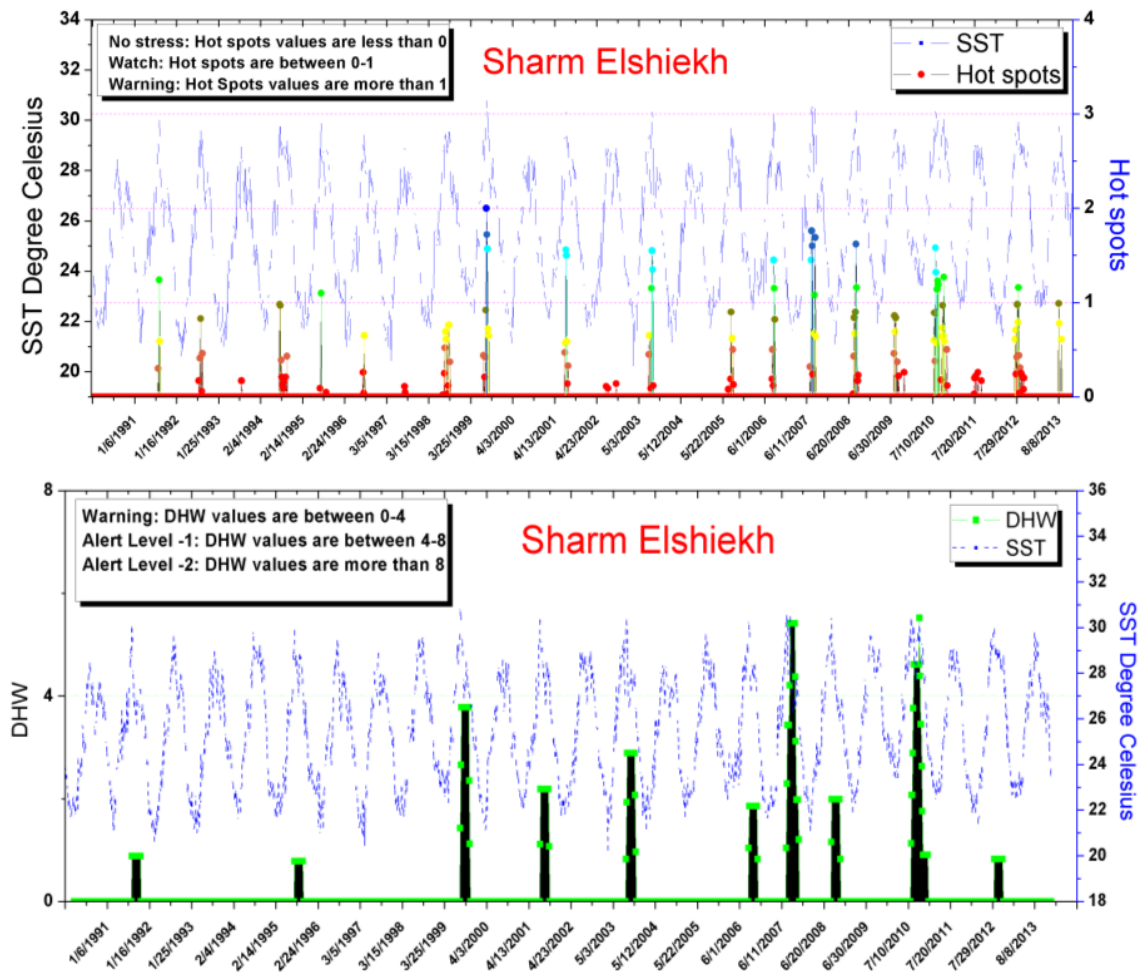

Fig. 8. Top: values of Hot Spots at Sharm El-Shiekh area (Note: For each year, Hot Spots values are represented in colours ranging from red to blue based on their relative intensity). Bottom: values of Degree Heating Weeks at Sharm El-Shiekh area during the last 23 years.

TABLE II: VALUES OF MMM AT EACH LOCATION

\begin{tabular}{ll}
\hline \hline Location & Maximum Monthly Mean (Degree Celsius) \\
\hline Newbaa & 27.357 \\
Sharm El-Shiekh & 28.779 \\
Hurghada & 28.703 \\
Qusir & 28.803 \\
Marsa Alam & 29.175 \\
Shalatin & 30.791 \\
\hline \hline
\end{tabular}

The results correspond to locations from north to south of the Egyptian Red Sea coast. In Newbaa, during the past 23 years, The results shows that it experienced a warning level based on the values of DHW less than 4 many years namely August 1995,1999,2001,2003,2005,2007.2008, and 2009. As shown in Fig. 7, the DHW values reach values more than 4 which imply that the warning level reaches Alert Level1 in 2012. Regarding Sharm El-shiekh, the maximum monthly mean was 28.779 degree Celsius. As most of the location on 
the Egyptian coast, most of the hot spots occur in August. Fig. 8 shows the coral bleaching warnings during the last 23 years. In 2007 and 2010, the warning level reaches level 1 when the values of DHW increase than 4. Based on the analysis of the remotely sensed Sea Surface Temperature (SST) data in Hurghada, the warning periods are presented in Fig. 9. In 2007 and 2010, the area experienced the highest values of
DHW. Regarding Qusir, August 2012 contained the highest value of DHW ever as shown in Fig. 10. The Maximum monthly Mean of Marsa-Alam was 29.175. As shown in Fig. 11 , it experienced some stresses on its coral reefs and reached warning level. Finally Shalatin has the highest MMM among the selected spots in the Egyptian Red Sea with 30.791 degree Celsius as shown in Fig. 12.
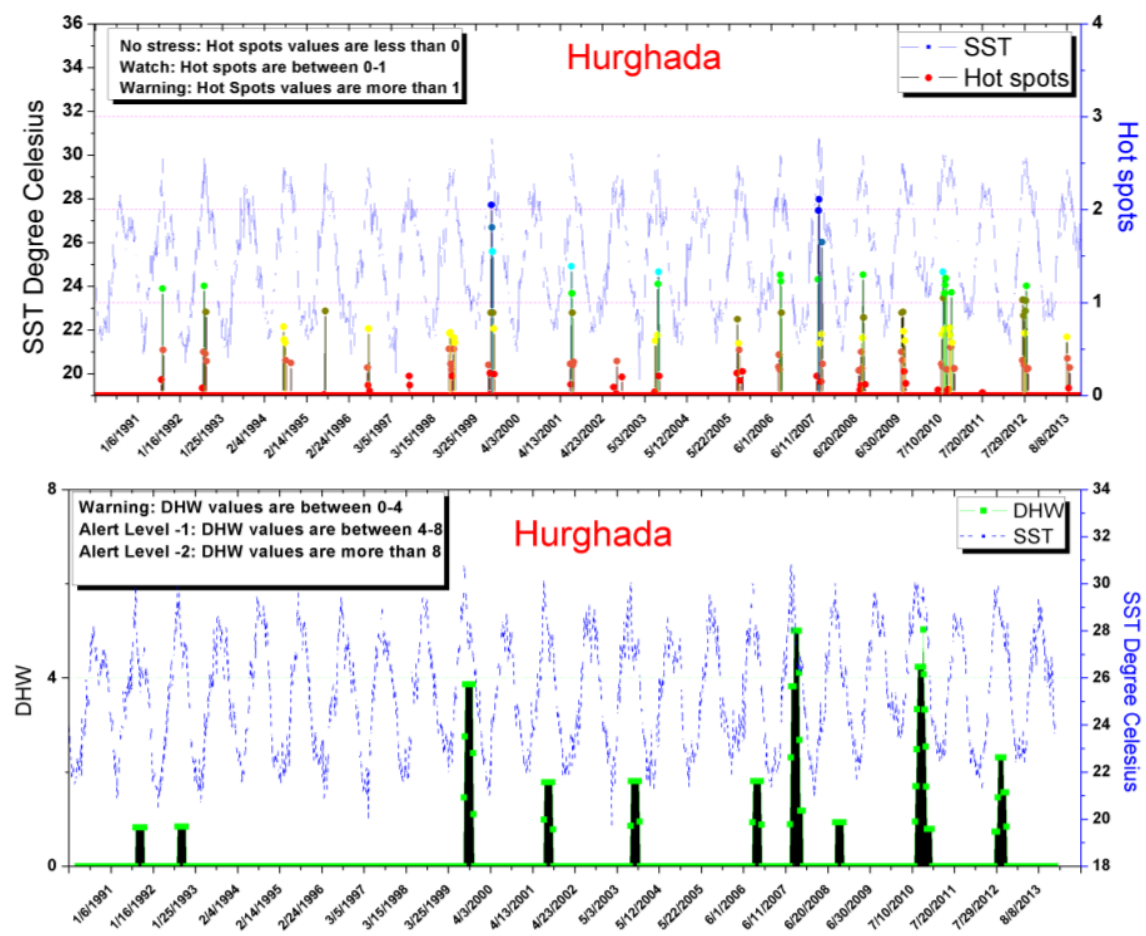

Fig. 9. On the left: values of Hot Spots at Hurghada area (Note: For each year, Hot Spots values are represented in colours ranging from red to blue based on their relative intensity). On the Right: values of Degree Heating Weeks at Hurghada area during the last 23 years.
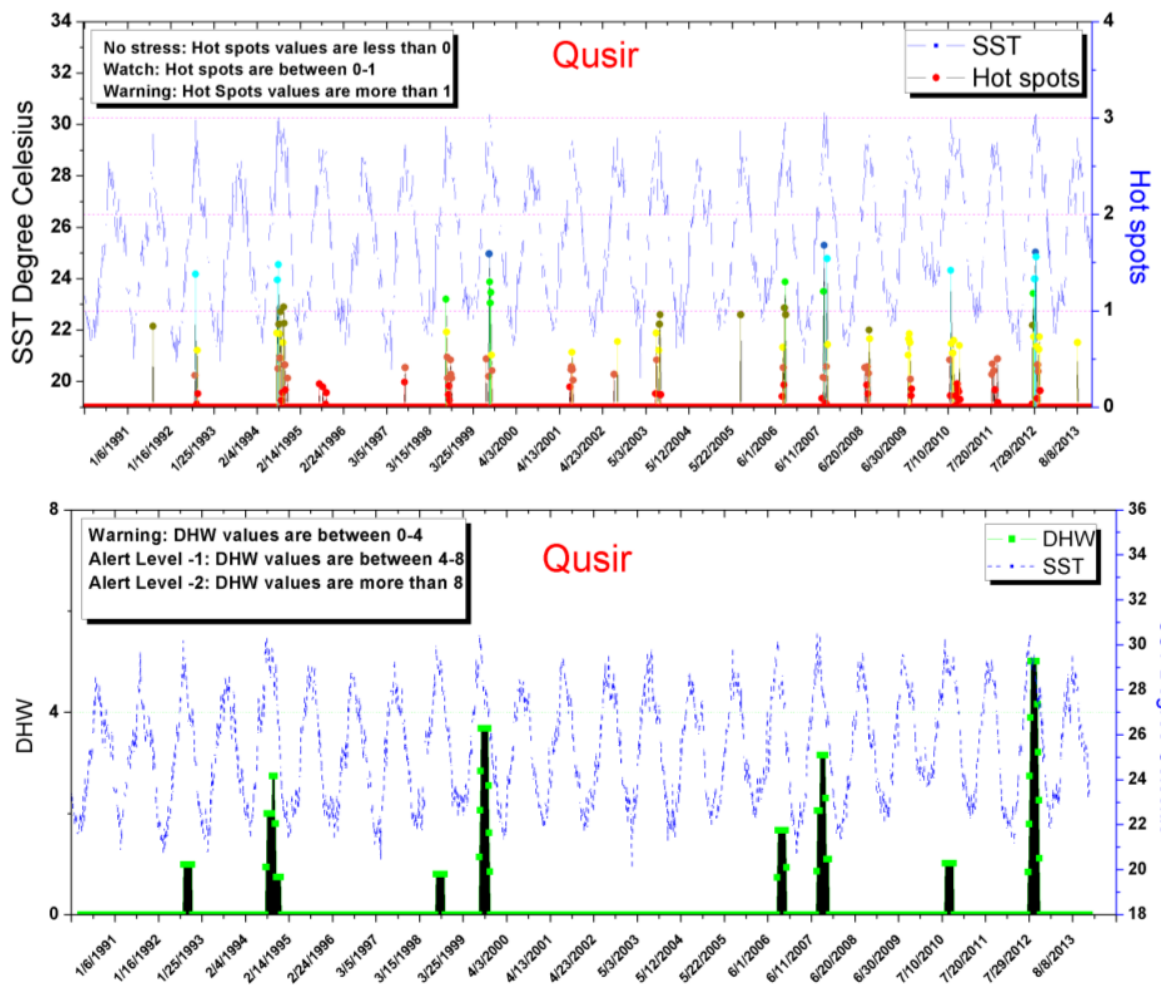

Fig. 10. Top: values of Hot Spots at Qusir area (Note: For each year, Hot Spots values are represented in colours ranging from red to blue based on their relative intensity). Bottom: Values of Degree Heating Weeks at Qusir area during the last 23 years.

To understand the pattern of sea surface temperature and by using the last 23 years of sea surface temperature (SST) data, the mean SST values (Part 1) and maximum sea surface temperature (Part 2) distributed over the study area are shown 
in Fig. 13. Some unique features can be concluded from these results. First, Suez gulf has the lowest mean SST among all other areas. The sea surface temperature in the western part of the Red Sea is much lower than the eastern part on the same latitude. Fig. 14 shows the standard deviation of sea surface temperature (part 1) and sea surface temperature anomaly
(SSTA) (part 2) based on whole the study period. The spatial distribution indicates that the richest spots of the coral reefs have the lowest standard deviation of SST. In addition the SSTA distribution indicates that the shallower areas have experienced some events of very high temperatures.
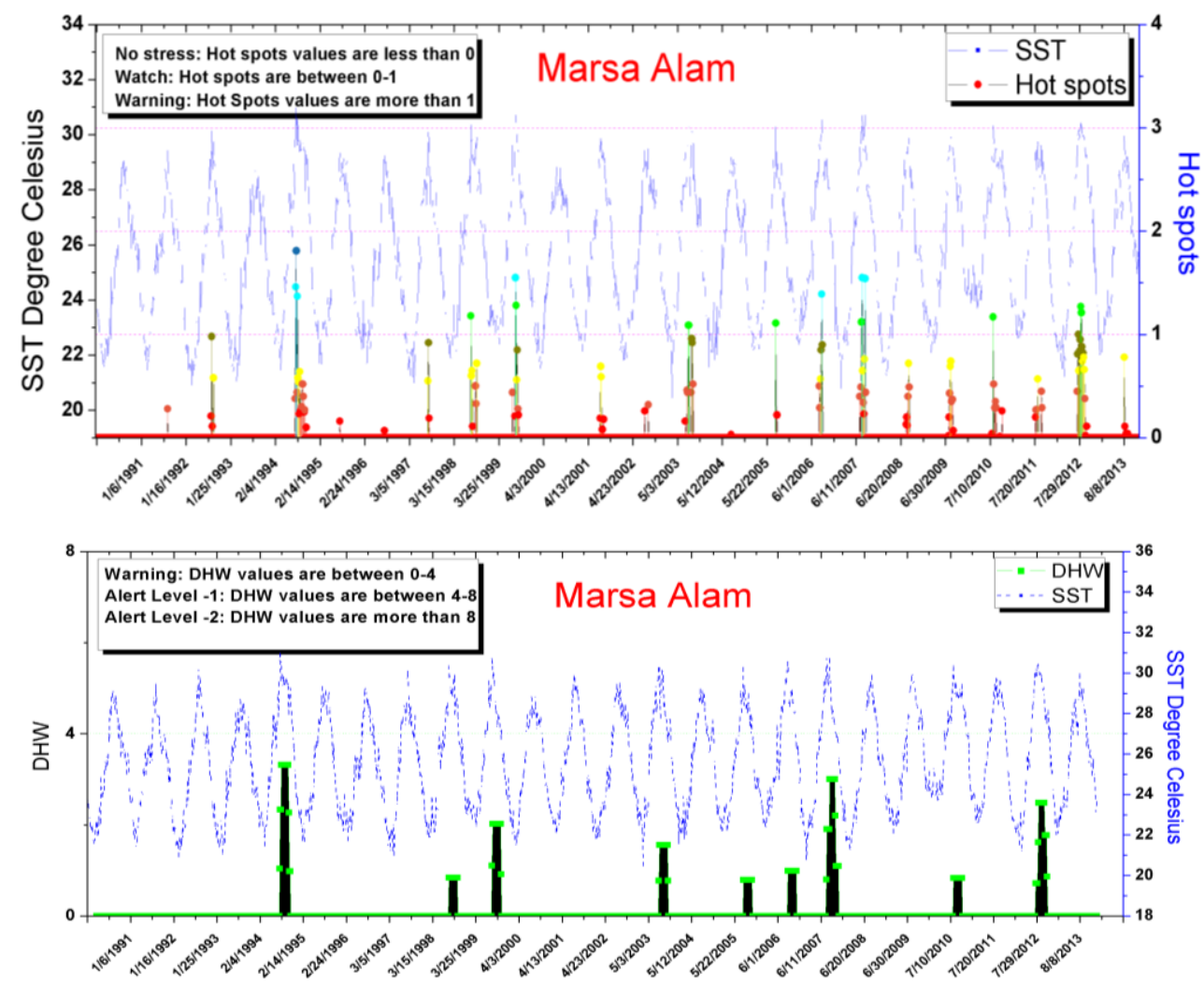

Fig. 11. Top: values of Hot Spots at Marsa Alam area (Note: For each year, Hot Spots values are represented in colours ranging from Red to blue based on their relative intensity), Bottom: values of Degree Heating Weeks at Marsa Alam area during the last 23 years.
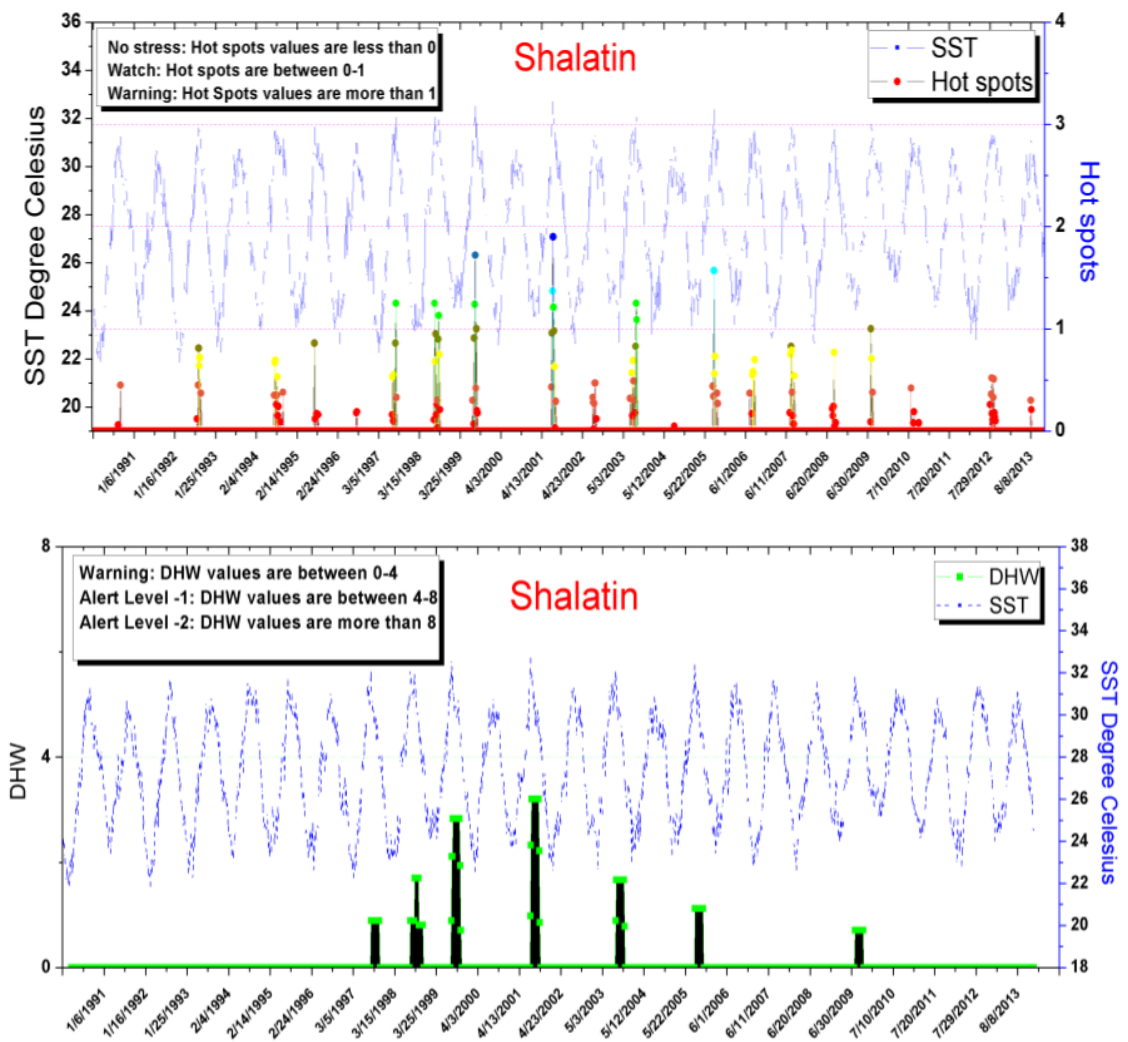

Fig. 12. Top: values of Hot Spots at Shalatin area (Note: For each year, Hot Spots values are represented in colours ranging from red to blue based on their relative intensity). Bottom: values of Degree Heating Weeks at Shalatin area during the last 23 years. 

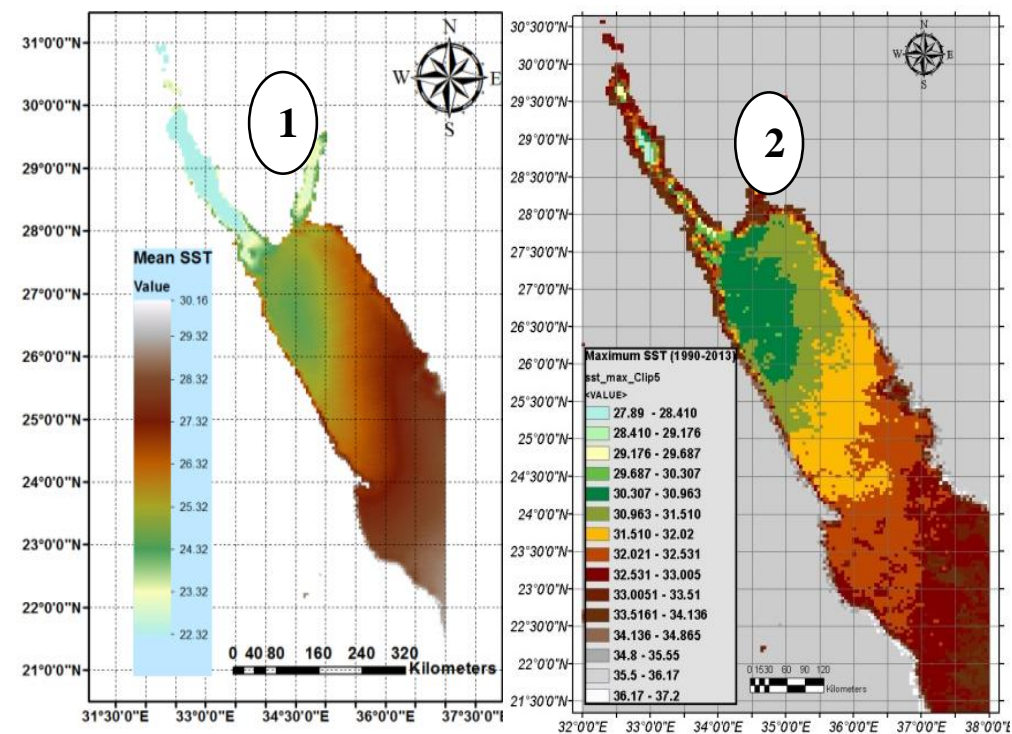

Fig. 13. Part 1: Spatial distribution of Mean sea surface temperature (SST) and. Part 2: Maximum Sea Surface Temperature based on daily.
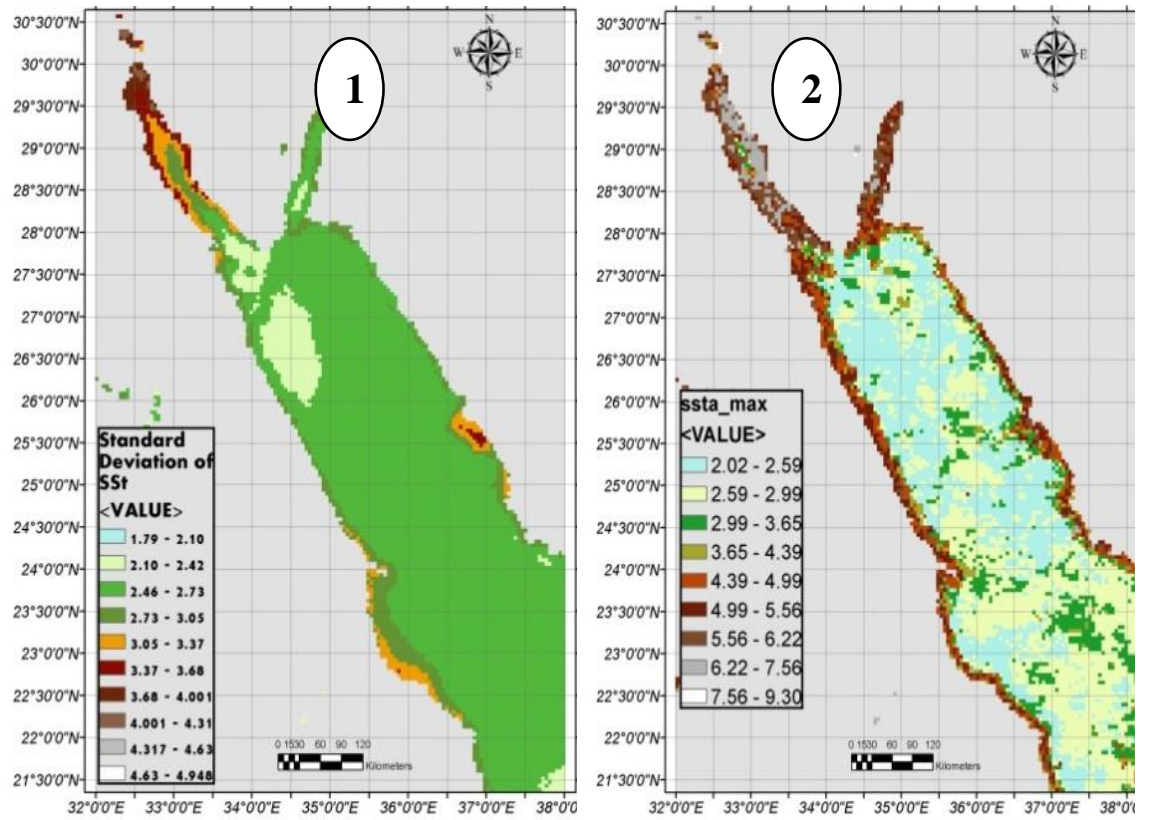

Fig. 14. Spatial distribution of standard deviation of sea surface temperature (SST) (Part 1) and maximum sea surface temperature anomalies (SSTA) based on daily data of the last 23 years of data (Part 2).

\section{CONCLUSIONS}

A This study includes a long term thermal analysis of some spots in the Egyptian Red Sea based on both in-situ measurements and remote sensing data. The spatial extent of bleaching warning was examined based on the analysis of Hot Spots (HS) and Degree Heating Weeks (DHW) parameters. This analysis is based on the available highest resolution sea surface temperature data after being validated using field measurements. This framework can be applied for early warning of coral bleaching in the future. This framework is suitable in areas where any increase in sea surface temperature has a direct impact on shallow water coral ecosystems. The threshold value should be calculated over the longest available periods of data. The annual and seasonal trends of sea surface temperature (SST) have been investigated. All the locations have positive annual and seasonal trends between $0.0207^{\circ} \mathrm{C} \mathrm{yr}^{-1}$ to $0.0371^{\circ} \mathrm{C} \mathrm{yr}^{-1}$. In the study, the threshold for coral reefs bleaching in the study sites was calculated. It started with 25.36 degree Celsius in
Newbaa and increases to 30.79 in the most south part in Shalatin. The work proved that there were some bleaching events in the last 23 years which weren't locally properly recorded such as 1999 and 2007 in some locations. In addition, the results showed an agreement with the recent recorded bleaching events in 2010, 2012. These results can act as a good reference for marine biologists who are interested in the historical bleaching events in the Egyptian coral reefs. The study reveals unique patterns of sea surface temperature in the western different from eastern part of the Red sea on the same latitude. This pattern need further research in terms of water movements. The applied framework in this study takes into account only the thermal stress so the study can be further enhanced by examining the local water flow patterns using any hydrodynamic modeling tools.

\section{ACKNOWLEDGMENT}

The first author is supported by a scholarship from the Mission Department, Ministry of Higher Education of the Government of Egypt which is gratefully acknowledged. The 
Hurghada Environmental Protection and Conservation Association (HEPCA) is also acknowledged for providing the measured sea surface temperature (SST) data. The first Author is also grateful for Dr Mohamed Shaltout (Department of Earth Sciences, University of Gothenburg) for some valuable comments on processing of the raster data.

\section{REFERENCES}

[1] L. M. Brander, P. Van Beukering, and H. S. J. Cesar, "The recreational value of coral reefs: A meta-analysis," Ecol. Econ., vol. 63, no. 1, pp. 209-218, Jun. 2007.

[2] R. Sea and C. Reefs, Economic Valuation of the Egyptian Red Sea Coral Reef Economic Valuation of the Egyptian, August 2003.

[3] T. Nakamura and R. Van Woesik, "Water-flow rates and passive diffusion partially explain differential survival of corals during the 1998 bleaching event," Mar. Ecol. Prog. Ser., vol. 212, pp. 301-304, 2001.

[4] K. NaXdaoka, Y. Nihei, R. Kumano, T. Yokobori, T. Omija, and K. Wakaki, "A field observation on hydrodynamic and thermal environments of a fringing reef at Ishigaki Island under typhoon and normal atmospheric conditions," Coral Reefs, vol. 20, no. 4, pp. 387-398, 2001.

[5] O. Hoegh-Guldberg, "Climate change, coral bleaching and the future of the world's coral reefs," Mar. Freshw. Res., vol. 50, no. 8, pp. 839-866, 1999.

[6] J. C. Bird, "Modelling Sub-reef thermodynamics to predict coral bleaching: A case study at scott reef, WA by," March 2005.

[7] B. B. Barnes, "The combined effects of light and temperature on coral bleaching: A case study of the florida reef tract using satellite data," University of South Florida, 2013.

[8] V. Barale and M. Gade, "Remote sensing of the African Seas," in Remote Sensing of the African Seas, 1st ed., V. Barale and M. Gade, Eds. Hamburg Germany: Springer NewYork Heidelberg Dordrecht London, 2013, pp. 317-337.

[9] O. E. Frihy, M. A. El Ganaini, W. R. El Sayed, and M. M. Iskander, "The role of fringing coral reef in beach protection of Hurghada, Gulf of Suez, Red Sea of Egypt," Ecol. Eng., vol. 22, no. 1, pp. 17-25, Feb. 2004.

[10] M. Spalding, C. Ravilious, and E. P. Green, World Atlas of Coral Reefs., Univ of California Press, 2001.

[11] M. Kotb, M. Abdulaziz, Z. Al-Agwan, K. Alshaikh, H. Al-Yami, A. Banajah, L. Devantier, M. Eisinger, M. Eltayeb, M. Hassan et al., "Status of coral reefs in the Red Sea and Gulf of Aden in 2004," Wilkinson, Op. Cit. Note, vol. 70, pp. 137-139, 2004.

[12] I. M. Shaalan, "Sustainable tourism development in the Red Sea of Egypt threats and opportunities," J. Clean. Prod., vol. 13, no. 2, pp. 83-87, Jan. 2005.
[13] N. Hilmi, A. Safa, and S. Reynaud, "Coral Reefs and Tourism in Egypt's Red Sea," Top. Middle East. North African Econ. Electron. J., vol. 14,2012

[14] H. I. El-Gamily, S. Nasr, and M. El-Raey, "An assessment of natural and human-induced changes along Hurghada and Ras Abu Soma Coastal Area, Red Sea, Egypt," Int. J. Remote Sens., vol. 22, no. 15, pp. 2999-3014, 2001.

[15] L. M. Burke, K. Reytar, M. Spalding, A. Perry et al., Reefs at Risk Revisited, World Resources Institute Washington, DC, 2011.

[16] Z. Moustafa, P. Hallock, M. S. Moustafa, and M. Z. Moustafa, "Observations of a Red Sea fringing coral reef under extreme environmental conditions," in Proc. 11th Int Coral Reef Symp., 2008, vol. 2, pp. 786-790.

[17] A. Mohamed, "Status of coral reef health in the northern Red Sea, Egypt," Int Coral Reef, pp. 9-13, July 2012.

[18] K. A. Furby, J. Bouwmeester, and M. L. Berumen, "Susceptibility of central Red Sea corals during a major bleaching event," Coral Reefs, vol. 32, no. 2, pp. 505-513, Jan. 2013.

[19] M. Hanafy and M. Ismail, "Climate change and its effect on the egyptian coast of the red sea: The first recorded coral mass bleaching event," Hurghada, 2014.

[20] B. P. Ferreira, M. B. S. F. Costa, M. S. Coxey, A. L. B. Gaspar, D. Veleda, and M. Araujo, "The effects of sea surface temperature anomalies on oceanic coral reef systems in the southwestern tropical Atlantic," Coral Reefs, vol. 32, no. 2, pp. 441-454, Dec. 2012.

[21] S. D. Donner, W. J. Skirving, C. M. Little, M. Oppenheimer, and O. V. E. Hoegh-Guldberg, "Global assessment of coral bleaching and required rates of adaptation under climate change," Glob. Chang. Biol., vol. 11, no. 12, pp. 2251-2265, 2005.

[22] G. Liu, A. E. Strong, and W. Skirving, "Remote sensing of sea surface temperatures during 2002 Barrier Reef coral bleaching," Eos, Trans. Am. Geophys. Union, vol. 84, no. 15, pp. 137-141, 2003.

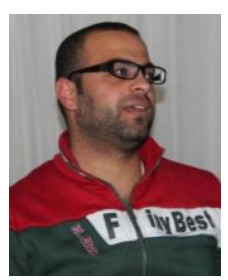

Ahmed Eladawy is a Ph.D. student at Egypt-Japan University of Science and Technology (E-JUST). He was born in Mansoura, Egypt, in June 1988. He obtained the B.Sc. degree in civil engineering from Mansoura University, Egypt, in 2010. His cumulative average grade is distinction with honor's degree. $\mathrm{He}$ got the master degree in environmental engineering. His research was about developing a coupled hydrodynamic water quality for a Northern Lake in Egypt. He is interested in the hydrodynamic modeling and applications of remote sensing in coastal areas. He is now working in a project aiming at developing an integrated mathematical and remote sensing approach for assessing anthropogenic impacts on natural resources of the Red Sea. 